\title{
Direct transcatheter mitral valve implantation in severe mitral annular calcification: technique and evidence
}

\author{
Michael I. Brener ${ }^{1}$, Isaac George ${ }^{2}$ \\ ${ }^{1}$ Division of Cardiology, New York Presbyterian Hospital-Columbia University Medical Center, New York, NY, USA; ${ }^{2}$ Division of Cardiothoracic \\ Surgery, New York Presbyterian Hospital-Columbia University Medical Center, New York, NY, USA \\ Correspondence to: Isaac George, MD. Division of Cardiothoracic Surgery, New York Presbyterian Hospital-Columbia University Medical Center, 177 \\ Fort Washington Avenue, 7 Garden North - Room 435, New York, NY 10032, USA. Email: ig2006@cumc.columbia.edu.
}

Submitted Mar 22, 2020. Accepted for publication Apr 07, 2020.

doi: $10.21037 /$ acs-2020-mv-12

View this article at: http://dx.doi.org/10.21037/acs-2020-mv-12

\section{Clinical vignette}

A 66-year-old woman was referred to our institution's heart team for evaluation of severe mitral annular calcification (MAC) leading to symptomatic mitral stenosis (MS). The patient had a history of hypertension and insulindependent diabetes mellitus, as well as end-stage renal disease for which she underwent a deceased donor renal transplant two years prior to presentation. Despite normal renal allograft function, the patient developed symptomatic atrial fibrillation and New York Heart Association class III heart failure symptoms, prompting hospitalization for acutely decompensated heart failure. Echocardiography demonstrated preserved bi-ventricular function as well as severe MAC that was encroaching on both mitral valve (MV) leaflets and producing severe MS. At a heart rate of 54 beats per minute, the mean gradient across the $M V$ was $7.2 \mathrm{mmHg}$, and the valve area measured $0.9 \mathrm{~cm}^{2}$ by planimetry. The patient's Society of Thoracic Surgeons (STS) risk score for valve replacement was $9.0 \%$. Given the patient's age and comorbidities, as well as the technical difficulties associated with intervening on such a calcified valve, the patient was offered direct transcatheter, transatrial implantation of an Edwards Sapien 3 bioprosthesis (Edwards Lifesciences, Irvine, CA, USA).

\section{Surgical technique}

\section{Preparation}

Pre-procedural echocardiography, as well as coronary angiography and cardiac-gated multi-detector computed tomography are essential (1). The latter is particularly important, in order to appropriately size the transcatheter heart valve (THV) and assess post-implantation risk of left ventricular outflow tract (LVOT) obstruction.

\section{Exposition}

A median sternotomy or right thoracotomy are performed first, followed by aortic and bi-caval cannulation, to facilitate cardiopulmonary bypass. Standard diastolic arrest with antegrade cardioplegia are induced. The left atrium is subsequently exposed through an opening in Waterson's groove.

\section{Operation}

To facilitate placement of the THV, the anterior MV leaflet is resected along with the supporting chordal structures. The posterior leaflet is typically left intact. If the risk of LVOT obstruction is high, a septal myectomy can be performed through a transverse aortotomy, prior to opening the left atrium. An Edwards Sapien S3 delivery system balloon is first used to size the annulus after leaflet resection, using the valve size predicted by CT reconstruction. Once the size is confirmed, the valve is prepared as follows: our technique, described elsewhere, involves sewing a felt strip around the sealing cuff of the THV with 5-0 Prolene sutures (1). The commissures are marked with a marking pen on the felt skirt. The valve is subsequently crimped onto the transcatheter delivery system. Prior to implantation, the atrial surface of the MV annulus circumference is lined with pledgeted 2-0 Ethibond sutures taken into leaflet tissue only. The THV is seated 
into the MV annulus and the valve balloon is inflated slowly, taking care to maintain proper orthogonal alignment with the annular plane, and orientation of the commissures at 2 , 6 and 10 o'clock. The pledgeted 2-0 Ethibond sutures are then passed through the sealing skirt and tied. Saline testing and later, transesophageal echocardiography are used to ensure the valve leaflets appropriately coapt and that there is minimal paravalvular leak (PVL) and no LVOT obstruction.

\section{Completion}

The left atrium is closed and de-aired, and the patient is weaned from cardiopulmonary bypass and decannulated in standard fashion. The chest is closed with sternal wires and chest tubes placed in the pleural space. A medication regimen involving lifelong Aspirin and a minimum of three months of anticoagulation with Warfarin, in order to achieve an International Normalized Ratio between 2.0 and 3.0, are recommended.

\section{Comments}

\section{Clinical results}

Patients who develop severe MAC are often elderly and poor surgical candidates on account of multiple comorbidities. Accordingly, outcomes with traditional valve replacement, with or without calcium debulking, are poor and the procedure is associated with a rare, but potentially fatal complication of posterior annular rupture $(2,3)$. Growing familiarity and experience with THVs has led to their use in valvulopathies other than aortic stenosis, including calcific MS. Percutaneous implantation of THVs in patients with severe MAC is feasible, but is associated with higher rates of complications, such as LVOT obstruction, severe PVL, and even embolization (4). Our group has previously reported the largest registry to date of patients undergoing transatrial TMVR, which uses the technique described above to secure the THV into the mitral annulus (5). Twenty-six patients enrolled across six sites were included in the analysis, which demonstrated a $100 \%$ technical success rate according to the Mitral Valve Academic Research Consortium criteria. Only one patient experienced mild PVL, which led to hemolysis and necessitated a follow-up procedure to dilate the THV and eliminate the PVL. All-cause mortality at 30 days occurred in $27 \%$ of patients, but the risk of LVOT obstruction was eliminated and implantation was achievable despite the patients' complex anatomy.

\section{Advantages}

Transatrial TMVR mitigates some of the risks associated with open surgical MV replacement in severe MAC. The procedure is shortened, limiting time on cardiopulmonary bypass, and the risks of posterior annular rupture and left circumflex artery injury are minimized. Relative to entirely percutaneous TMVR techniques, transatrial TMVR also reduces the likelihood of LVOT obstruction, severe PVL and device embolization.

\section{Caveats}

Patients with severe MAC remain at high risk for poor outcomes following any intervention because of accumulated comorbidities: transatrial TMVR is no different, and the short-term mortality remains high in the early experiences documented with this procedure. Patients with concomitant valvular heart disease requiring intervention represent a particularly high-risk group of patients for whom transatrial TMVR should be evaluated with caution. Specific anatomic considerations, which influence the risk of LVOT obstruction for example, also need to be considered for optimal patient selection. Finally, valve durability and hemodynamic performance relative to traditional surgical valves may be inferior, emphasizing the need for long-term follow-up with patients undergoing transatrial TMVR.

\section{Acknowledgments}

Funding: None.

\section{Footnote}

Conflicts of Interest: The authors have no conflicts of interest to declare.

Open Access Statement: This is an Open Access article distributed in accordance with the Creative Commons Attribution-NonCommercial-NoDerivs 4.0 International License (CC BY-NC-ND 4.0), which permits the noncommercial replication and distribution of the article with the strict proviso that no changes or edits are made and the original work is properly cited (including links to both the formal publication through the relevant DOI and the license). 
See: https://creativecommons.org/licenses/by-nc-nd/4.0/.

\section{References}

1. Russell HM, Guerrero ME, Salinger MH, et al. Open Atrial Transcatheter Mitral Valve Replacement in Patients With Mitral Annular Calcification. J Am Coll Cardiol 2018;72:1437-48.

2. Ben-Avi R, Orlov B, Sternik L, et al. Short- and longterm results after prosthetic mitral valve implantation in patients with severe mitral annulus calcification $\dagger$. Interact Cardiovasc Thorac Surg 2017;24:876-81.

Cite this article as: Brener MI, George I. Direct transcatheter mitral valve implantation in severe mitral annular calcification: technique and evidence. Ann Cardiothorac Surg 2021;10(1): 183-185. doi: 10.21037/acs-2020-mv-12
3. Casarotto D, Bortolotti U, Thiene G, et al. Rupture of the posterior wall of the left ventricule after replacement of the mitral valve: a description of 8 cases (author's transl). G Ital Cardiol 1977;7:387-94.

4. El Sabbagh A, Eleid MF, Foley TA, et al. Direct transatrial implantation of balloon-expandable valve for mitral stenosis with severe annular calcifications: early experience and lessons learned. Eur J Cardiothorac Surg 2018;53:162-9.

5. Praz F, Khalique OK, Lee R, et al. Transatrial implantation of a transcatheter heart valve for severe mitral annular calcification. J Thorac Cardiovasc Surg 2018;156:132-42. 